\title{
Multi-Level Contact Oxidation Process Performance When Treating Automobile Painting Wastewater: Pollutant Removal Efficiency and Microbial Community Structures
}

\author{
Yufang Zhu ${ }^{1}$, Tong Zhu ${ }^{1, *}$, Michael Groetzbach ${ }^{2}$, Hui Han ${ }^{2}$ and Yongguang $\mathrm{Ma}^{3}$ \\ 1 School of Mechanical Engineering \& Automation, Northeastern University, Shenyang 110819, China; \\ zhuyufang66@163.com \\ 2 BMW Brilliance Automotive Ltd., Shenyang 100044, China; searchab@163.com (M.G.); \\ Hui.Han.ab@bmw-brilliance.cn (H.H.) \\ 3 Liaoning Provincial Machinery Research Institute Co., Ltd., Shenyang 110032, China; hanhui_21@126.com \\ * Correspondence: tongzhu@mail.neu.edu.cn; Tel.: +86-024-84554981
}

Received: 28 September 2017; Accepted: 9 November 2017; Published: 11 November 2017

\begin{abstract}
This study applied a multi-level contact oxidation process system in a pilot-scale experiment to treat automobile painting wastewater. The experimental wastewater had been pre-treated through a series of physicochemical methods, but the water still contained a high concentration of chemical oxygen demand (COD) and had poor biodegradability. After the biological treatment, the COD concentration of effluent could stay below $300 \mathrm{mg} / \mathrm{L}$. The study analyzed the effects of hydraulic residence time (HRT) on COD, ammonia nitrogen $\left(\mathrm{NH}_{4}{ }^{+}-\mathrm{N}\right)$, and total nitrogen (TN). The optimal HRT was $8 \mathrm{~h}$; at that time, removal efficiencies of COD, ammonia nitrogen, and total nitrogen were $83.8 \%, 86.3 \%$, and $65 \%$, respectively. The system also greatly reduced excess sludge production; the removal efficiency was $82.8 \%$ with a HRT of $8 \mathrm{~h}$. The study applied high-throughput pyrosequencing technology to evaluate the microbial diversity and community structures in distinct stages of the biological reactor. The relevance between process performance and microbial community structure was analyzed at the phylum and class level. The abundant Firmicutes made a large contribution to improving the biodegradability of painting wastewater through hydrolysis acidification and reducing sludge production through fermentation in the biological reactor.
\end{abstract}

Keywords: multi-level contact oxidation process; painting wastewater treatment; process performance; microbial community; high-throughput pyrosequencing

\section{Introduction}

The automobile industry has rapidly developed, prompting significant interest in automobile painting wastewater treatment. New solutions will help auto manufacturers to control water environmental pollution.

Automobile painting processes generate different kinds of wastewater, from activities such as degreasing, activation, passivation, electrophoresis, acid cleaning, and alkaline cleaning. Since a number of chemical materials are applied during these processes, the wastewater is characterized by high concentrations of organics, heavy metal, suspended solids, as well as a low biodegradability index, which is extremely hazardous in environment [1]. The concentration of automobile painting wastewater varies widely, and is decided by many factors, like discharge cycles, production and cleaning process, types of chemical used, etc. The typical characteristics of automobile painting wastewater are as follows: $\mathrm{pH}$ is in the range of between 6 and 12, chemical oxygen demand (COD) is $1400-5900 \mathrm{mg} / \mathrm{L}$, 
BOD (Biochemical Oxygen Demand) is $100-350 \mathrm{mg} / \mathrm{L}$, suspended solid is $400-700 \mathrm{mg} / \mathrm{L}$, and total heavy metals is $20-45 \mathrm{mg} / \mathrm{L}[2,3]$. The complicated organic constituents, such as surface-active agents, electrophoretic paint, and fossil oils, are very difficult to remove and biodegrade.

Several physicochemical methods have been implemented to treat such wastewater. Common methods include coagulation-flocculation, dissolved air flotation, microfiltration, gravity sedimentation, reverse osmosis, and other advanced treatment methods [1,4], such as ozone oxidation, membrane filtration, and electrochemical oxidation [5-7]. However, these physicochemical methods often need the consumption of numerous chemicals and generate amounts of toxic sludge, which requires additional treatment [8]. Biological treatment processes have been considered as a reasonably efficient technology to treat the wastewater of paint industries, being both economical and eco-friendly [9]. The activated sludge process, anaerobic filters, and bio-filters are common biological treatment processes $[10,11]$. Physicochemical methods, combined with biological technology, are widely used to treat automobile painting wastewater, because they optimize both economic and treatment efficiency.

Discharge standards for auto manufacturer effluent have become increasingly strict, especially for COD concentration. Therefore, the pollutant removal efficiency of painting wastewater treatment processes should be enhanced, in order to diminish the pressure on the subsequent wastewater treatment [12].

In recent years, the multi-level contact oxidation process (MLCOP) to treat wastewater has received increased worldwide attention and popularity. The MLCOP reactor consists of six equally sized contact oxidation tanks. The differences in pollutant composition and concentration in each tank leads to generating different kinds of microorganisms, so the design of separated structure in the MLCOP reactor is conducive to the biota separation, and could diminish the interspecific competition. The microbial community in each tank could stay in a relatively stable condition, and gradually form a food chain. Therefore, the various pollutants in wastewater could be decreased, step by step, through the metabolism and interaction of microorganisms in the balanced ecosystem. The sludge yield was reduced efficiently, due to the predation of high trophic level microbes and the energy loss during biomass conversion. Besides, the biofilms also play an important role on the interception and degradation of suspended solid, so that the wastewater could become clear gradually along the flow direction in the reactor [13,14].

So, MLCOP is an innovative development of the conventional contact oxidation process, and has distinctive advantages, such as lower running cost, smaller cover space, a lower sludge yield coefficient, and a higher treatment efficiency.

However, there have been no relevant studies applying MLCOP to treat painting wastewater. Therefore, this study applied MLCOP to further treat real painting wastewater that had been pre-treated by a series of physiochemical processes. With the practical engineering goal of reducing the cover space and running cost, modifying the existing processes is primarily oriented towards achieving a higher COD removal efficiency. The target COD concentration in effluent should be less than $300 \mathrm{mg} / \mathrm{L}$, based on the integrated wastewater discharge standard of Liaoning Province [15].

Previous research on MLCOP has mainly focused on treatment performance and the influence of process parameters. There is little available information on microbial community composition as well as the relevance between process performance and microbial community in the MLCOP system. As such, this study applies high-throughput pyrosequencing technology to comprehensively describe the dynamic change of the microbial community in the MLCOP system [16].

We believe this study is unique in its investigation of changes in microbial community structures when treating painting wastewater with MLCOP. The study results offer a better visualization and understanding of the variation of the complete microbial community in the MLCOP reactor from a microbiological perspective. It could be demonstrated that the microbial diversity and community composition change dynamically in different stages to respond to the changes in the living environment, so the results could be taken as reference for future research about further optimizing the process 
parameters and achieving better treatment efficiency. Besides, the analysis about the relationship between the microbial community structure and process performance may support future engineering projects in automobile painting wastewater treatment. Considering the requirements of high treatment efficiency and cost saving, the application of MLCOP system and study findings provide a new way for industries to treat automobile painting wastewater with high concentrations of pollutants.

\section{Materials and Methods}

\subsection{Experimental Wastewater}

The wastewater used for this experiment was sourced from a painting shop of an automobile manufacturer in Shenyang, China; the raw painting wastewater had been pre-treated by a series of physiochemical methods, as shown in Figure 1 [17]. The heavy metals were largely removed by the pretreatment, such that zinc is less than $0.5 \mathrm{mg} / \mathrm{L}$ and nickel is less than $0.1 \mathrm{mg} / \mathrm{L}$. The effluent from the interim storage tank (Figure 1) was used for the experimental wastewater, and it was further treated by the new added MLCOP system. The aim of the present study was to analyze the treatment performance of the MLCOP system and the microbial community structures in it. Table 1 lists the characteristics of the experimental wastewater.

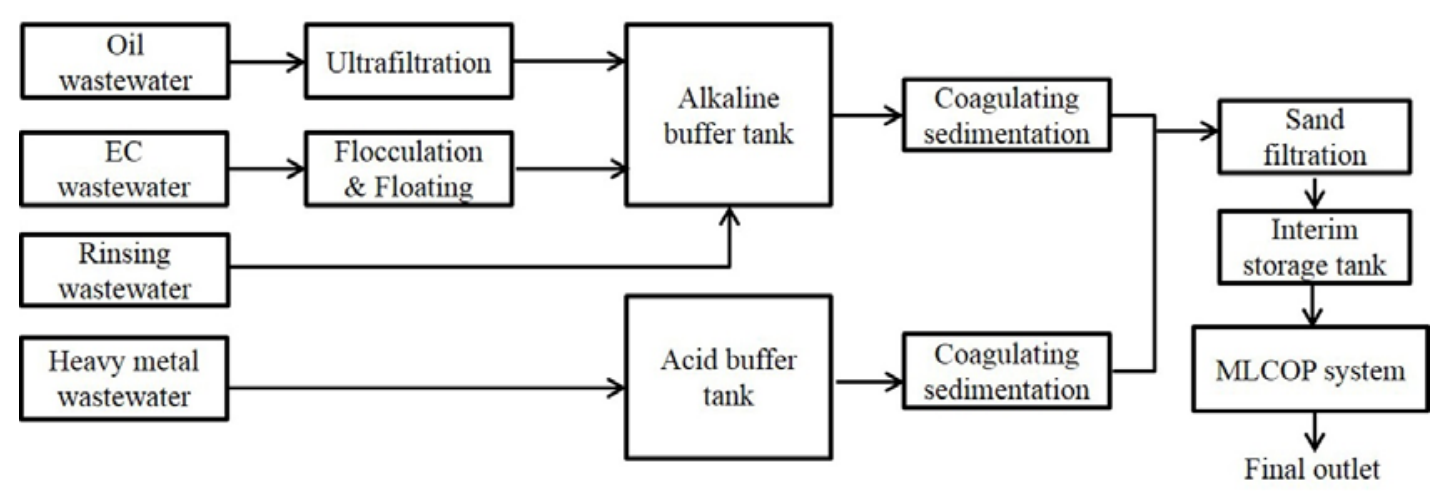

Figure 1. Flowchart of the painting wastewater treatment process with the new added multi-level contact oxidation process (MLCOP) system.

Table 1. Quality of wastewater used for experiment.

\begin{tabular}{cccccccc}
\hline Main Pollutant & $\mathbf{p H}$ & $\begin{array}{c}\mathbf{C O D}_{\mathrm{Cr}} \\
(\mathbf{m g} / \mathbf{L})\end{array}$ & $\begin{array}{c}\mathbf{B O D}_{\mathbf{5}} \\
(\mathbf{m g} / \mathbf{L})\end{array}$ & $\begin{array}{c}\mathbf{T P}^{\mathbf{a}} \\
(\mathbf{m g} / \mathbf{L})\end{array}$ & $\begin{array}{c}\mathbf{T N} \\
(\mathbf{m g} / \mathbf{L})\end{array}$ & $\begin{array}{c}\mathbf{N H}_{\mathbf{4}}{ }^{+}-\mathbf{N} \\
(\mathbf{m g} / \mathbf{L})\end{array}$ & $\begin{array}{c}\mathbf{S S}^{\mathbf{b}} \\
(\mathbf{m g} / \mathbf{L})\end{array}$ \\
\hline $\begin{array}{c}\text { Test value } \\
\text { Discharge standard }\end{array}$ & $7 \pm 0.5$ & $1200 \pm 50$ & $180 \pm 10$ & $0.5 \pm 0.1$ & $30 \pm 5$ & $10 \pm 2$ & $150 \pm 10$ \\
\end{tabular}

a TP: Total Phosphorus; ${ }^{\mathrm{b}}$ SS: Suspended Solid.

\subsection{Experimental Apparatus}

A pilot-scale MLCOP system was used to treat the painting wastewater. Figure 2 shows the flow process.

The bioreactor was constructed by plexiglass, with $90 \mathrm{~cm}$ length, $25 \mathrm{~cm}$ width, and $45 \mathrm{~cm}$ height. The total effective volume for the experiment was $80 \mathrm{~L}$. It included six equally sized biological tanks, labeled A, B, C, D, E, and F. There was an open space $(8 \mathrm{~cm} \times 8 \mathrm{~cm})$ in the top left corner or the bottom right corner of each baffle plate alternately. The wastewater could flow up and down in the bioreactor. The goal of a reactor design like this is to ensure enough contact between the pollutants and the microorganisms. A carrier frame was placed in each biological tank, and polyethylene mixed carriers with a compact and porous fiber structure were fixed on each carrier frame. The biological 
carrier was produced by Japanese Teijin Company, and the appearance of the biological carrier is shown in Figure 3. The main technical parameters of biological carriers are shown in Table 2.

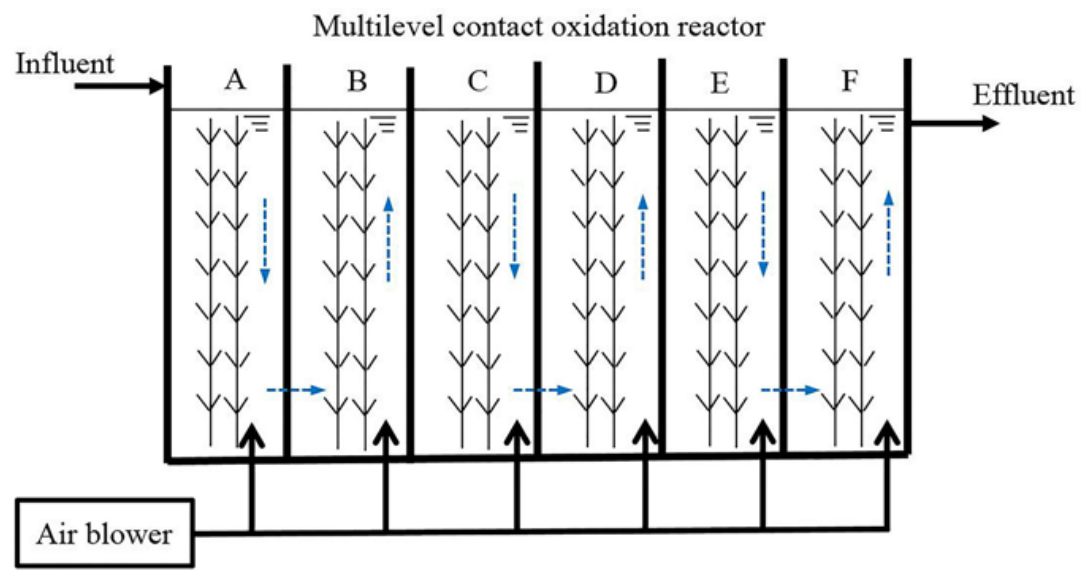

Figure 2. Experimental system of the multi-level contact oxidation process.

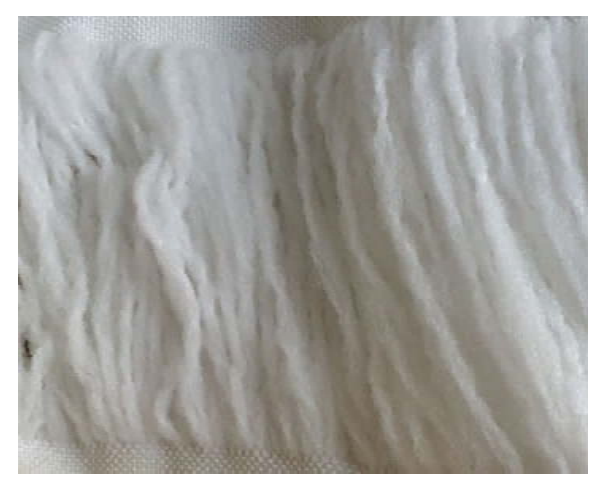

Figure 3. The appearance of biological carrier.

Table 2. The technical parameters of biological carriers.

\begin{tabular}{cc}
\hline Carrier Parameters & Value \\
\hline Filling quantity & $4.2 \mathrm{~kg} / \mathrm{m}^{3}$ \\
Filling ratio & $20 \%$ \\
Volume density & $21 \mathrm{~kg} / \mathrm{m}^{3}$ \\
Specific surface area & $1200 \mathrm{~m}^{2} / \mathrm{kg}$ \\
Porosity & $97 \%$ \\
\hline
\end{tabular}

The aeration system was placed on the bottom of each biological tank and brought air into the biological tank through the air blower. The aeration intensity was controlled by an aeration valve which could be adjusted according to the changes of water quality, flowrate, and the growth state of the biofilm [17]. The aeration rate was in the range of 0.18 to $0.40 \mathrm{~m}^{3} / \mathrm{h}$ to ensure sufficient dissolved oxygen. Wastewater and microorganism samples were collected for analysis from tanks B, D, and F, representing three reactor stages.

\subsection{Experimental Set-Up Procedure}

The inoculation sludge applied for the experiment was the sludge from a general sewage treatment plant associated with automobile manufacturing. The plant has operated using an anoxic/oxic process for several years. The MLSS (mixed liquid suspended solids) of the initial dosing sludge was 
approximately $3 \mathrm{~g} / \mathrm{L}$. Volumes of $25 \mathrm{~L}$ active sludge, $30 \mathrm{~L}$ painting wastewater, and $25 \mathrm{~L}$ clean water were mixed and then inoculated into the biological reactor. The dissolved oxygen was controlled at $2.0-4.0 \mathrm{mg} / \mathrm{L}$; the water temperature in the reactor was $25-30^{\circ} \mathrm{C}$.

Two days later, the surface of biological carrier in each tank was fully and evenly covered by active sludge, and a layer of mud-yellow biofilm was growing. This demonstrated successful biofilm formation.

Afterwards, the experimental wastewater started to constantly flow into the biological reactor through the water pump. The flow rate, controlled by the flowmeter, started at $80 \mathrm{~L} / \mathrm{d}$, and gradually increased to $240 \mathrm{~L} / \mathrm{d}$. In other words, the hydraulic residence time (HRT) started at $24 \mathrm{~h}$ and was gradually reduced to $8 \mathrm{~h}$. Experimental set-up and stable operation took a total of 200 days [17]. The biomass of each tank was relatively steady, and decreased gradually. The MLSS for suspended growth in tanks B, D, and F was $205-245 \mathrm{mg} / \mathrm{L}, 95-130 \mathrm{mg} / \mathrm{L}$, and 32-48 mg/L, respectively. The MLSS for attached growth in tanks B, D, and F was $3350-3620 \mathrm{mg} / \mathrm{L}, 2570-2840 \mathrm{mg} / \mathrm{L}$, and $1860-2110 \mathrm{mg} / \mathrm{L}$, respectively.

\subsection{Analytical Methods}

The influent and effluent from three reactor stages (tanks B, D, and F) were sampled every day. Key indicators, including $\mathrm{COD}$, biochemical oxygen demand $\left(\mathrm{BOD}_{5}\right)$, total nitrogen, ammonia nitrogen, and suspended sludge (SS), were measured in accordance with the standard methods [18]. The dissolved oxygen (DO) was measured using a dissolved oxygen meter (HQ30D, Hach, Loveland, CO, USA); the $\mathrm{pH}$ was measured by a pH330 meter (WTW, Munich, Germany). Each data point represented the average value of three measurements.

\subsection{Bacterial Community Analysis}

\subsubsection{Sample Collection}

When the COD concentration of the final effluent remained below $300 \mathrm{mg} / \mathrm{L}$ stably, and the change range of COD removal rate was less than $1 \%$, the biological reactor was considered to have achieved stable operation. Once the biological reactor achieved stable operation at a HRT of $8 \mathrm{~h}$, four activated sludge samples were collected for microbial community structure analysis. This included the inoculation sludge sample (IS), and three activated sludge samples from tanks B, D, and F (BS, DS, and FS, respectively). Each sample was mixed with $50 \%$ ethanol after collection, immediately placed on icepacks for transport, and stored at $-80^{\circ} \mathrm{C}$ until the next step [19].

\subsubsection{DNA Extraction and PCR Amplification}

Genomic DNA was extracted using the E.Z.N.A. ${ }^{\circledR}$ Stool DNA Kit (Omega Bio-tek, Norcross, GA, USA) according to the manufacturer's protocols. The electrophoresis detection was conducted with $1 \%(\mathrm{w} / \mathrm{v})$ agarose gel. The agarose gel DNA purification kit was used for the separation and extraction of DNA fragments, and the NanoDrop 2000 spectrophotometer (Wilmington, DE, USA) was used for the quantification of extracted DNA. The samples after DNA extraction were kept at $-20^{\circ} \mathrm{C}$ for amplification.

The primer set for amplification was 515F (5'-GTGCCAGCMGCCGCGG-3') and 907R (5'-CCG TCAATTCMTTTRAGTTT-3'). The reaction conditions for the PCR amplification were as follows: 30 cycles of denaturation at $95^{\circ} \mathrm{C}$ for $30 \mathrm{~s}$, annealing at $50{ }^{\circ} \mathrm{C}$ for $30 \mathrm{~s}$, extension at $72{ }^{\circ} \mathrm{C}$ for $50 \mathrm{~s}$, and final extension at $72{ }^{\circ} \mathrm{C}$ for $10 \mathrm{~min}$ [20].

\subsubsection{Pyrosequencing and Sequence Data Analysis}

All the reads achieved through PCR amplification from each sample were merged in equal concentrations, and were sequenced using a Roche FLX454 pyrosequencing machine (Branford, CT, USA). In order to ensure high quality reads, just the first $350 \mathrm{bp}$ after primer F515 of each sequence were 
selected for the next step of analysis. Operational taxonomic units (OTU) clustering at $97 \%$ similarity was carried out with the MOTHUR program (Ann Arbor, MI, USA) [20]. From the cluster file, the Chao1 estimator, Shannon index, and Good's coverage for each sample were obtained by MOTHUR. A BLAST taxonomic classification was performed on the phylum and class level using MOTHUR and the SILVA106 database [21].

\section{Results and Discussion}

\subsection{Process Performance}

The average COD concentration in the influent was approximately $1200 \mathrm{mg} / \mathrm{L}$ throughout the experiment. The HRT was sequentially set at $24 \mathrm{~h}, 20 \mathrm{~h}, 16 \mathrm{~h}, 12 \mathrm{~h}$, and $8 \mathrm{~h}$. Each time the HRT was shortened, the MLCOP reactor was not stable, and needed time to adapt to the change. During the adaption period, the COD removal rate experienced a similar trend at different stages: it first decreased, then increased quickly, and finally stabilized [17]. The fluctuation was the largest in tank B, and the smallest in tank F. This is because the COD concentration of the influent in tank B was higher than the concentration in tanks D and F. This led to a larger impact on the microorganisms in tank B.

As the influent flow rate increased, the microorganisms in each biological tank quickly adapted to the changing environmental conditions, achieving stable operation. This demonstrated that the MLCOP reactor was highly resistant to the impact of changes in flowrate.

After the MLCOP reactor achieved stable operations at each HRT condition, the following 20 day test was conducted. The average COD concentrations of the effluent from tanks B, D, and F, and the $\mathrm{COD}$ removal rates, were evaluated. Figure 4 shows the results. Each COD value was the average value of 20 days' test results.

Figure 4 shows a significant difference in COD concentration between the biological tanks. The microorganisms in the first two biological tanks played the primary role in degrading the organic substances. The experimental test results demonstrated that the COD concentration of the final effluent remained stable below $300 \mathrm{mg} / \mathrm{L}$.

In addition to COD concentration, other effluent indicators also reached discharge standards during the experiment. For example, through previous physicochemical treatment processes, total nitrogen and ammonia nitrogen decreased to $30 \mathrm{mg} / \mathrm{L}$ and $10 \mathrm{mg} / \mathrm{L}$, respectively. To consistently reach the discharge standard, the MLCOP system removed these substances further, reaching levels below $10.5 \mathrm{mg} / \mathrm{L}$ and $1.4 \mathrm{mg} / \mathrm{L}$, respectively, at different HRTs (Figure 5).

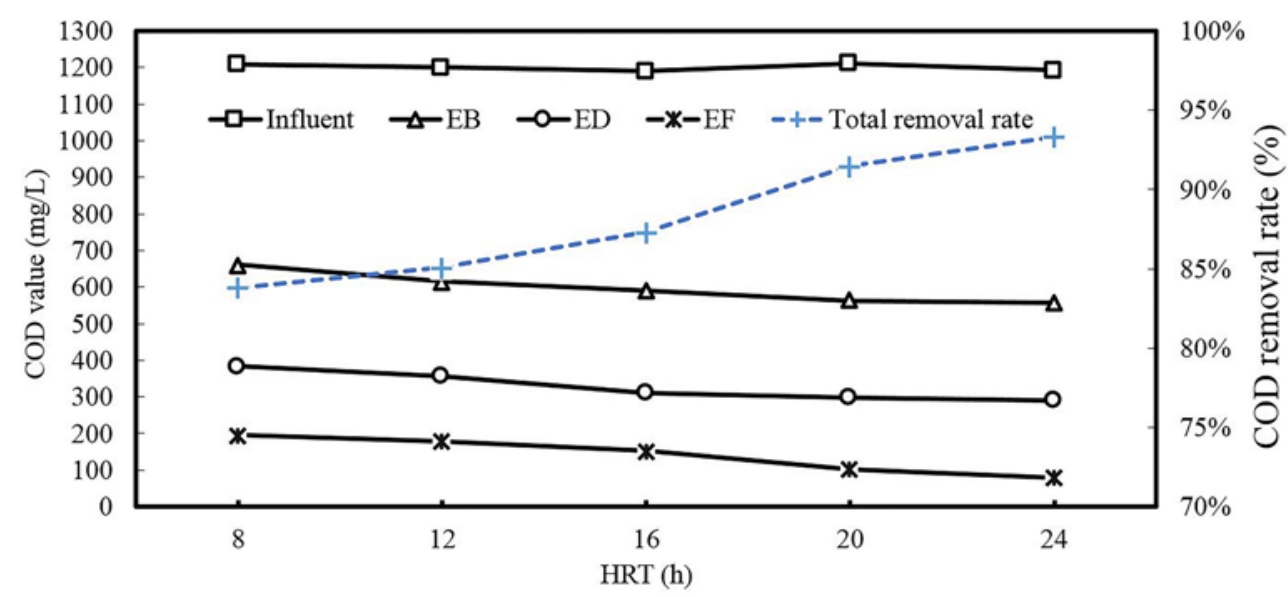

Figure 4. Variations in COD concentration and total removal rate at different HRTs.

As the HRT decreased, the total COD removal rate in the MLCOP reactor gradually decreased. Removal rates were $93.3 \%$ at a HRT of $24 \mathrm{~h} ; 91.5 \%$ at a HRT of $20 \mathrm{~h} ; 87.3 \%$ at a HRT of $16 \mathrm{~h} ; 85.1 \%$ at a 
HRT of $12 \mathrm{~h}$; and $83.8 \%$ at a HRT of $8 \mathrm{~h}$. When the HRT was set at $4 \mathrm{~h}$, the MLCOP reactor had difficulty reaching a stable state. The COD concentration of the effluent fluctuated widely, and sometimes exceeded the target of $300 \mathrm{mg} / \mathrm{L}$. Therefore, comprehensively considering the operation cost, treatment capacity, and efficiency, $8 \mathrm{~h}$ was identified as a more suitable and lower HRT to remove COD in the MLCOP reactor.

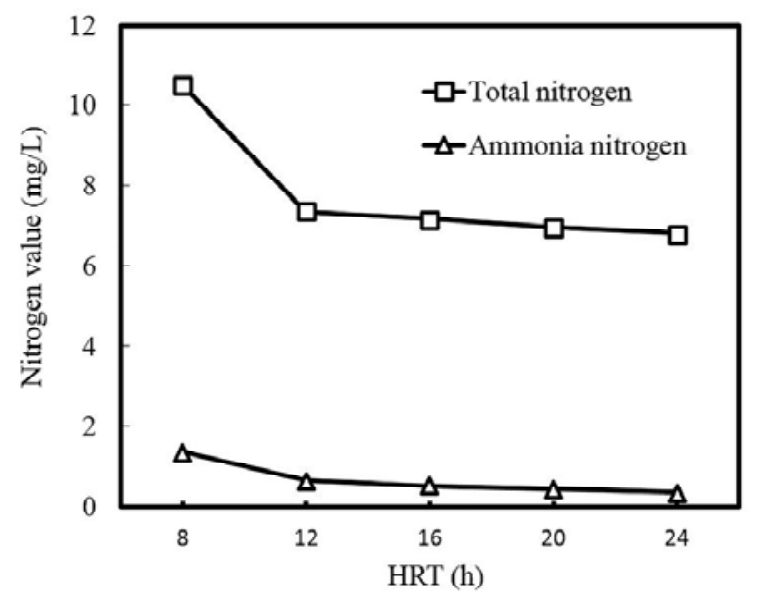

Figure 5. Variations in total nitrogen and ammonia nitrogen of the effluent at different HRTs.

Nitrogen removal in biological treatment processes requires both aerobic and anoxic environments. The results may indicate that ammonia nitrogen was first converted into nitrite or nitrate through oxidation in an aerobic environment. Then, the nitrite or nitrate was transformed into nitrogen gas in an anoxic environment, which probably existed in the inner part of the biological carriers or biofilm. The available literature also showed that under suitable conditions, the simultaneous nitrification and denitrification (SND) could occur during the aerobic treatment process, because there existed limitation to oxygen diffusion, and it could cause the formation of an anoxic environment [22,23].

Previous research demonstrated that the carbon source with suitable concentration control could facilitate SND, because the external carbon source could act as electron donor and stimulate the nitrogen removal by denitrification [24,25]. It could be inferred that the different concentration of carbon source in each biological tank may have an active effect on the nitrogen removal.

The removal efficiency of total nitrogen and ammonia nitrogen were positively correlated to the HRT. As the HRT was sequentially set at $24 \mathrm{~h}, 20 \mathrm{~h}, 16 \mathrm{~h}, 12 \mathrm{~h}$, and $8 \mathrm{~h}$, the removal efficiency of total nitrogen was $77.3 \%, 76.8 \%, 76.1 \%, 75.5 \%$, and $65.0 \%$, respectively; the removal efficiency of ammonia nitrogen was $96.5 \%, 95.7 \%, 94.9 \%, 93.6 \%$, and $86.3 \%$ respectively. The removal efficiencies of total nitrogen were lower than ammonia nitrogen at HRTs. This can be attributed to a restrained denitrification reaction under oxic conditions. This suggests that only part of the nitrate could be transferred to the anoxic environment where the denitrification occurred [23].

In general, using only an aerobic biological process to biodegrade the refractory organic matter is difficult and expensive. Therefore, anaerobic processes are usually used beforehand to improve wastewater biodegradation. This allows organic substances to be more easily degraded further by the aerobic biological process. Currently, hydrolysis acidification combined with aerobic biological process is relatively common when treating automobile painting wastewater to biodegrade organic substances [8]. Nevertheless, anaerobic systems are usually larger than aerobic ones because of low biological treatment efficiency in anaerobic conditions. This requires additional construction or space costs for anaerobic systems.

Considering economic and technological limitations, the MLCOP system in this paper was used to biologically treat automobile painting wastewater to improve pollutant removal efficiency and obtain higher effluent quality. When the biological system reached stable operation with the HRT of 
$8 \mathrm{~h}$, the variations of BOD and COD versus time are shown in Figure 6. The BOD, COD, and SS of influent and effluent from three stages were also assessed. Table 3 shows the average values.
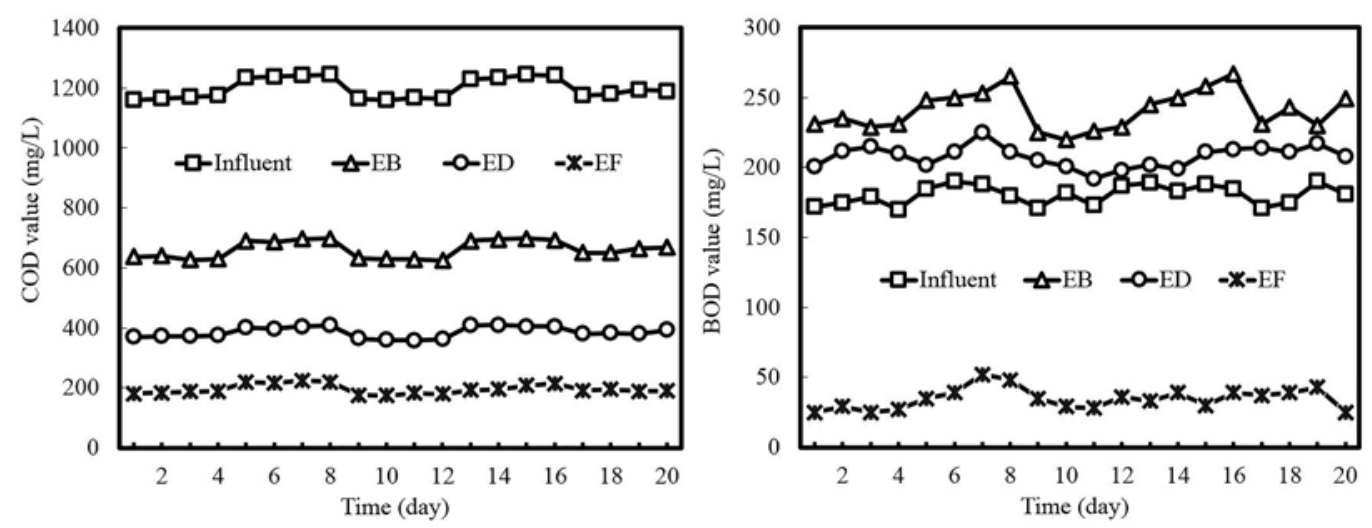

Figure 6. Variations of BOD and COD versus time in different tanks with an HRT of $8 \mathrm{~h}$.

Table 3. The average COD, BOD, and SS concentrations in different tanks and removal efficiency with an HRT of $8 \mathrm{~h}$.

\begin{tabular}{cccccc}
\hline Items & Influent & $\mathbf{E B}^{\mathbf{a}}$ & $\mathbf{E D}^{\mathbf{b}}$ & $\mathbf{E F}^{\mathbf{c}}$ & Total Removal Ratio $^{\mathbf{c}}$ \\
\hline BOD & 180 & 240 & 208 & 35 & $80.6 \%$ \\
COD & 1200 & 661 & 385 & 195 & $83.8 \%$ \\
BOD/COD & 0.15 & 0.36 & 0.54 & 0.18 & - \\
SS & 145 & 186 & 78 & 25 & $82.8 \%$ \\
\hline
\end{tabular}

${ }^{\mathrm{a}}$ EB: effluent from tank $\mathrm{B} ;{ }^{\mathrm{b}}$ ED: effluent from tank D; ${ }^{\mathrm{c}} \mathrm{EF}$ : effluent from tank F.

The BOD/COD ratio of influent was approximately 0.15 , indicating that the raw painting wastewater was very hard to biodegrade. However, the total BOD removal ratio was approximately $80.6 \%$; the BOD/COD ratio improved during biological treatment. In particular, the BOD/COD ratio of the effluent in tanks B and D increased to 0.36 and 0.54 , respectively. This is maybe because the special biological carriers, with a compact and porous fiber structure, could retain a high biomass concentration and established an anoxic microenvironment in the inner section. This facilitated the transformation of macromolecule organic substances to small molecular organic compounds through hydrolysis acidification.

Approximately $28 \mathrm{~m}^{3}$ painting wastewater was treated during the experiment, however, less than $1 \mathrm{~kg}$ of excess effluent sludge was collected, and the average SS removal ratio was $82.8 \%$. The excess sludge yield of the MLCOP system was approximately $0.03 \mathrm{~g} \mathrm{SS}\left(\mathrm{g} \mathrm{COD}_{\text {removed }}\right)^{-1}$, while the excess sludge yield of the conventional activated sludge treatment process was reported to be $0.2-0.4 \mathrm{~g}$ SS $\left(\mathrm{g} \mathrm{COD}_{\text {removed }}\right)^{-1}[26,27]$. Only around $10 \%$ sludge production of conventional activated sludge treatment processes was obtained in the MLCOP system. Besides, the SS of final effluent from the biological reactor was low, and could reach the discharge requirement. There was no sedimentation tank and no sludge recycle in this system. This indicates the MLCOP system could efficiently reduce the excess sludge production compared to the conventional activated sludge treatment processes.

\subsection{Microbial Community Structure Analysis}

The process performance of the MLCOP system was significantly influenced by microbial behaviors. This highlights the need to analyze and demonstrate the relationship between the microbial community structure and pollutant degradation from a microbiological perspective. Therefore, further research was conducted to assess the impacts of microbial community on MLCOP performance. 
The high-throughput pyrosequencing technology was applied in this study to investigate the characteristics of microbial communities in different stages of the MLCOP reactor. This allowed the identification of several sequences, and provided comprehensive information about the microbial communities. This could offer a better visualization and understanding of the variation of the complete microbial community in the MLCOP reactor.

\subsubsection{Microbial Abundance and Diversity}

The high-throughput pyrosequencing technology generated 119,644 high-quality sequences from the four samples, including the inoculation sludge sample (IS), and three activated sludge samples from tanks B, D, and F (BS, DS, and FS, respectively). The quantity of sequences obtained in each sample was distinct: 26,160 (IS); 34,650 (BS); 27,345 (DS); and 31,489 (FS). Sequence trimming barely had an impact on the analysis of the microbial community, and was performed for each sample to support alignment and normalization [19]. The remaining 26,160 sequences for each sample were used for further study on the microbial community.

The Chao estimator was used to characterize species richness, with a higher value indicating greater richness. The Shannon index was used to estimate species diversity and evenness, with a higher value indicating higher diversity and evenness. High biodiversity is assumed to enhance ecosystem stability, based on the ecology principle. Coverage was used to determine the possibility that the following read would be included in the obtained OTU (Operational Taxonomic Units), with a higher value representing larger possibility [24]. The coverage was greater than 0.995 in each sample, suggesting that the sequencing data from samples were sufficiently representative and authentic.

In Table 4, IS stood for the inoculation sludge sample. The inoculation sludge was from a general sewage treatment plant, and the plant had operated using an anoxic/oxic process for several years. Therefore, the sequencing results of IS could represent those of the standard activated sludge.

Table 4 shows that when the MLCOP system reached stable operation, the Chao estimator and Shannon estimator of BS, DS, and FS all decreased compared with those of IS. This suggests that microbial community richness and diversity in the MLCOP system were less than those in standard activated sludge (IS). In the MLCOP system, the Chao estimator and Shannon index were highest for DS and lowest for BS. This suggests that the microbial community of the middle stage exhibited larger richness and higher diversity than the others in the MLCOP system. Given that the entire biological reactor ran under identical operating conditions, variations in microbial community structure largely depended on the influent water quality of each tank.

Table 4. Species diversity and richness estimators for the four samples.

\begin{tabular}{ccccc}
\hline Sample ID & OTU & Chao & Shannon & Coverage \\
\hline IS & 678 & 750 & 5.19 & 0.9965 \\
BS & 391 & 532 & 3.78 & 0.9967 \\
DS & 558 & 705 & 4.54 & 0.9951 \\
FS & 525 & 631 & 4.15 & 0.9962 \\
\hline
\end{tabular}

In the first stage, the influent had the greatest impact on the microbial community. This stage had the highest concentration of refractory poisonous organic compounds, and the lowest biodegradability. Based on the decomposition of specific microorganisms, many macromolecule organic substances were degraded into smaller molecular organic compounds, improving biodegradability. In the middle stage, influent impact was reduced, increasing the survival and abundance of the microbial community. In the last stage, influent impact on the microbial community was the lowest. This is because the easily biodegradable organics had been consumed in the previous stages. As such, the lack of organic nutrients also restrained growth and enrichment of the microbial community. 


\subsubsection{Microbial Community Composition}

To observe the microbial community variation in different stages, the microbial community structure and composition were analyzed on the phylum and class level.

Figure 7 shows that, on the phylum level, the microorganisms in the reactor's distinct stages were from similar dominant phyla, but there were different abundances of each phylum. In total, 10 phyla were detected. The main phyla were similar in each sample; Proteobacteria, Bacteroidetes, Firmicutes, and Chloroflexi, and represented $83 \%$ in IS, $96 \%$ in BS, $91 \%$ in DS, and $94 \%$ in FS, respectively. This indicates that the main four phyla may be enriched in painting wastewater treatment, and play a critical role in pollutant removal.

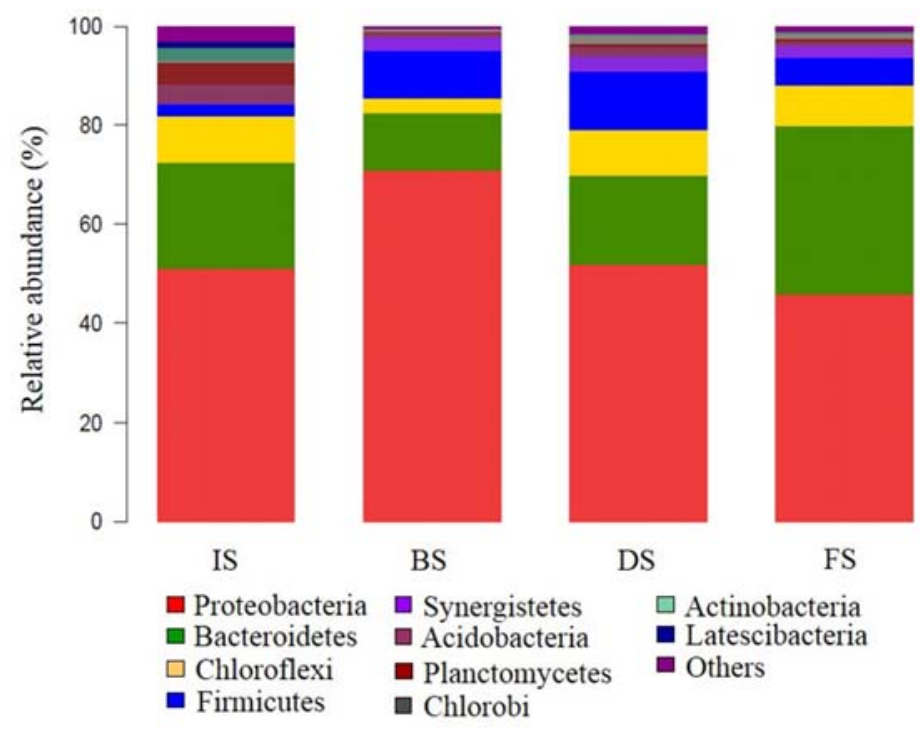

Figure 7. Microbial community structure and composition by phylum in samples from the MLCOP reactor.

The dominant phylum in each sample was Proteobacteria; this finding is consistent with previous studies [28]. Most of Proteobacteria belonged to facultative anaerobic heterotrophic bacteria, using organics as a carbon source during the wastewater treatment process. Proteobacteria were highly enriched and they were particularly high in BS, accounting for $71 \%$ of the total microbial composition. The relative abundance of Proteobacteria in DS and FS was decreased, in turn, compared to sample BS, which was consistent with the change trend of COD concentration, as shown in Figure 4. As wastewater flowed sequentially through each tank, the differences in pollutant composition and concentration in each tank may have facilitated the change of microbial composition. This may suggest that microorganisms with different species and structures could efficiently decompose the refractory organic matter step by step in each tank.

Bacteroidetes decreased to $12 \%$ in BS and $18 \%$ in DS; for comparison, they were present at $21 \%$ in IS. However, Bacteroidetes were significantly enriched in FS (34\%). This finding suggests that the influent wastewater with higher concentrations of COD and toxic organic substances in BS and DS may restrain Bacteroidete enrichment.

Firmicutes were more abundant in samples BS (10\%), DS (12\%), and FS (6\%) compared to sample IS $(2 \%)$. Firmicutes have a relatively thick cell wall, increasing resistance to desiccation and extreme environments [29,30]. Firmicutes are also reported to have hydrolytic and acidogenic abilities [31]. Table 3 shows that the changes in the BOD/COD ratio in different stages were aligned with changes in Firmicutes. This suggests that Firmicutes were closely associated with macromolecule organic substance degradation, and could significantly contribute to improving wastewater biodegradability in the MLCOP system's hydrolysis acidification. 
Clostridium, in this study, was the main subdivision of Firmicutes at class level. Although Clostridium was not the major OTU in sample BS, Clostridium were more abundant in samples BS ( $8 \%)$, DS (9\%), and FS (5\%), compared to sample IS (1\%). Besides, Clostridium was reported to enable consumption and decrease of excess sludge efficiently through fermentation [32]; this outcome corresponds with the low excess sludge production in this study. Thus, Firmicutes may have a profound impact on sludge reduction in the MLCOP system.

Members of Chloroflexi played an ecological role in degrading cellular materials and carbohydrates. Figure 7 shows that Chloroflexi in BS was reduced from $9 \%$ to $3 \%$; this was mainly due to the sharp impact of the highly polluted influent wastewater. This validates the previous observation that the microbial structure in the first stage was less stable than in the subsequent stages.

The four samples had similar dominant phylum and main microbial compositions at the phylum level; however, discrepancy among samples turned out to be more evident on the class level. This level provided more information on the dynamic changes and of microbial community structure in each sample. Figure 8 shows that the most dominant class in the initial phase was $\gamma$-Proteobacteria. However, after stable operations, the dominant classes in different stages shifted dynamically and became more distinct; these classes were $\beta$-Proteobacteria in BS, $\alpha$-Proteobacteria in DS, and Sphingobacteria in FS.

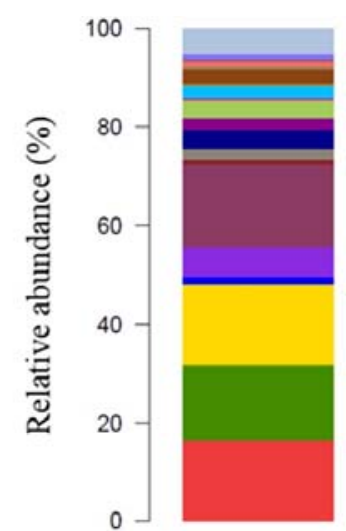

IS

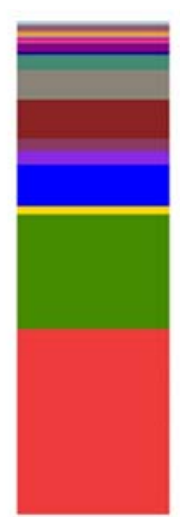

BS

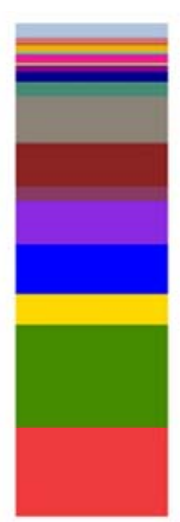

DS

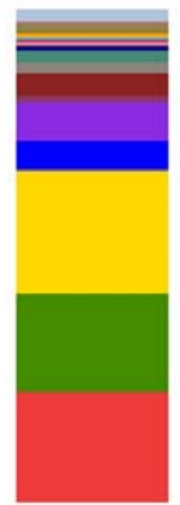

FS

\begin{tabular}{|c|c|c|}
\hline $\begin{array}{l}\text { Betaproteobacteria } \\
\text { Alphaproteobacteria } \\
\text { Sphingobacteria } \\
\text { Bacteroidia } \\
\text { Anaerolineae } \\
\text { Gammarproteobacteria } \\
\text { Clostridia }\end{array}$ & $\begin{array}{l}\text { Deltaproteobacteria } \\
\text { Synergistia } \\
\text { Acidobacteria } \\
\text { - Flavobacteria } \\
\text { Planctomycetacia } \\
\text { Q Negativicutes } \\
\text { Actinobacteria }\end{array}$ & $\begin{array}{l}\text { Chlorobia } \\
\text { Caldilineae } \\
\text { Cytophagia } \\
\text { Bacilli } \\
\text { घ Epsilonproteobacteria } \\
\text { L Latescibacteria_norank } \\
\text { O Others }\end{array}$ \\
\hline
\end{tabular}

Figure 8. Microbial community structure and composition, by class, in samples from the MLCOP reactor.

Sphingobacteria, classified as a subdivision of Bacteroidetes, was present at an abundance of $16 \%$ in IS. However, it decreased to $1 \%$ in BS, and $6 \%$ in DS, and was enriched in FS at an abundance of $25 \%$. This may be because the bacteria were inhibited by the toxicity of influent with high COD concentrations.

The distributions of the main dominant classes, including $\alpha$-Proteobacteria, $\beta$-Proteobacteria, $\gamma$-Proteobacteria, and Sphingobacteria, were relatively similar, and even in IS, but became heterogenous at different proportions in the other three samples. In particular, $\alpha$-Proteobacteria and $\beta$-Proteobacteria were largely enriched in BS, compared with other class compositions.

Proteobacteria mainly included four subdivisions on the class level: $\alpha$-Proteobacteria, $\beta$-Proteobacteria, $\gamma$-Proteobacteria, and $\delta$-Proteobacteria. In previous studies, $\beta$-Proteobacteria were identified as the largest class of Proteobacteria in sewage wastewater treatment systems [19]. However, 
in this study, the class compositions in Figure 9 show the discrepancies in Proteobacteria from different reactor stages.

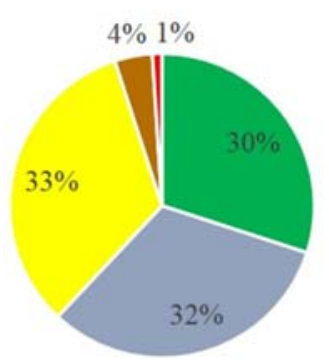

IS

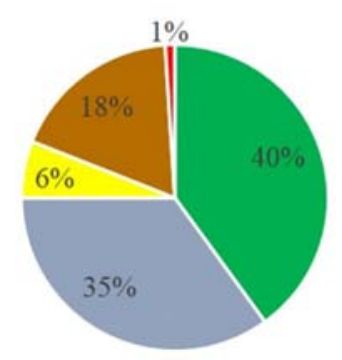

DS

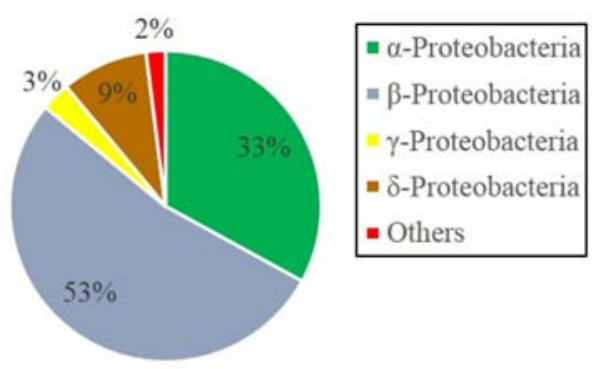

BS

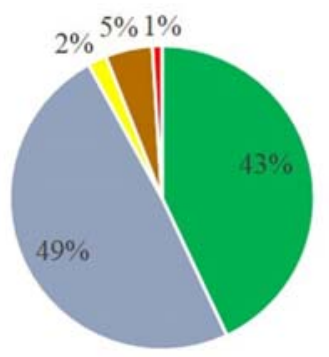

FS

Figure 9. Class compositions of Proteobacteria in four stages of the MLCOP reactor.

Study results suggest that the microbial community structures in different tanks dynamically and flexibly shifted their compositions to adapt to the relevant living environments at different pollutant concentrations [33]. During the extended acclimation to the painting wastewater, some bacteria that survived in the inoculation sludge could not adapt to the influent water quality; these bacteria were gradually eliminated in each level of the reactor.

\section{Conclusions}

In this study, a MLCOP system was used to further treat painting wastewater. The process performance indicated that this biological system could efficiently degrade the remaining refractory organic substances in painting wastewater. As the HRT was reduced, the total COD removal rate gradually decreased. At the optimal HRT of $8 \mathrm{~h}$, the COD removal efficiency was $83.8 \%$. The ammonia nitrogen and total nitrogen were also further reduced in the reactor. After the MLCOP treatment, all the pollutant indicators of effluent could meet the integrated discharge standards. This method significantly improved wastewater biodegradability, reduced excess sludge production during the operational period, and was very cost-effective.

Under long-term treatment, the microbial diversity and community composition significantly shifted in different stages, suggesting that the microbial community changed dynamically and flexibly to respond to changes in the living environment. The relevance between process performance and microbial community structure was analyzed on the phylum and class level. The abundant Firmicutes contributed to improving painting wastewater biodegradability through hydrolysis acidification, and may play an important role in reducing sludge through fermentation in the MLCOP reactor.

This study demonstrated that the MLCOP system is an attractive technological option that decreases the COD concentration of painting wastewater. It has low maintenance requirements, a simple structure, and needs only a small cover space. Given these advantages, this method could serve as an effective subsequent biological treatment process to further lower the COD concentration 
of painting wastewater, with positive economic and social benefits. The study results may support future engineering projects in automobile painting wastewater treatment.

Acknowledgments: This research was supported by the National Natural Science Foundation of China (51408105), the Fundamental Research Funds for the Central Universities of China (N140306001) and the Doctoral Scientific Fund Project of China (20130042110009).

Author Contributions: Yufang Zhu conceived the experiments; Yufang Zhu, Yongguang Ma and Hui Han performed the experiments; Yufang Zhu analyzed the data and wrote the original paper; Tong Zhu and Michael Groetzbach contributed in the discussion of results and revised the paper. All authors participated in reading and finalizing the paper.

Conflicts of Interest: The authors declare no conflict of interest. The founding sponsors had no role in the design of the study; in the collection, analyses, or interpretation of data; in the writing of the manuscript, and in the decision to publish the results.

\section{References}

1. Dey, B.K.; Hashim, M.A.; Hasan, S.; Gupta, B.S. Microfiltration of water-based paint effluents. Adv. Environ. Res. 2004, 8, 455-466. [CrossRef]

2. Güven, D.; Hanhan, O.; Aksoy, E.C.; Insel, G.; Çokgör, E. Impact of paint shop decanter effluents on biological treatability of automotive industry wastewater. J. Hazard. Mater. 2017, 330, 61-67. [CrossRef] [PubMed]

3. Oliveira, R.P.; Ghilardi, J.A.; Ratusznei, S.M.; Rodrigues, J.A.D.; Zaiat, M.; Foresti, E. Anaerobic sequencing batch biofilm reactor applied to automobile industry wastewater treatment: Volumetric loading rate and feed strategy effects. Chem. Eng. Process. 2008, 47, 1374-1383. [CrossRef]

4. Balik, O.Y.; Aydin, S. Coagulation/flocculation optimization and sludge production for pre-treatment of paint industry wastewater. Desalin. Water Treat. 2016, 57, 12692-12699. [CrossRef]

5. Lopez-Grimau, V.; Gutierrez, M.C. Decolourisation of simulated reactive dyebath effluents by electrochemical oxidation assisted by UV light. Chemosphere 2006, 62, 106-112. [CrossRef] [PubMed]

6. Zhang, J.C.; Giorno, L.; Drioli, E. Study of a hybrid process combining PACs and membrane operations for antibiotic wastewater treatment. Desalination 2006, 194, 101-107. [CrossRef]

7. Akyol, A. Treatment of paint manufacturing wastewater by electrocoagulation. Desalination 2012, 285, 91-99. [CrossRef]

8. Krithika, D.; Philip, L. Treatment of wastewater from water based paint industries using submerged attached growth reactor. Int. Biodeterior. Biodegrad. 2016, 107, 31-41. [CrossRef]

9. Mathur, A.K.; Majumder, C.B. Biofiltration and kinetic aspects of a biotrickling filter for the removal of paint solvent mixture laden air stream. J. Hazard. Mater. 2008, 152, 1027-1036. [CrossRef] [PubMed]

10. Schoenberg, T.; Veltman, S.; Switzenbaum, M. Kinetics of anaerobic degradation of glycol-based type I aircraft deicing. Biodegradation 2001, 12, 59-68. [CrossRef] [PubMed]

11. Liu, H.; Yang, F.; Wang, T.; Liu, Q.; Hu, S. Carbon membrane-aerated biofilm reactor for synthetic wastewater treatment. Bioproc. Biosyst. Eng. 2007, 30, 217-224. [CrossRef] [PubMed]

12. Choi, Y.Y.; Baek, S.R.; Kim, J.I.; Choi, J.W.; Hur, J.; Lee, T.U.; Park, C.J.; Lee, B.J. Characteristics and Biodegradability of Wastewater Organic Matter in Municipal Wastewater Treatment Plants Collecting Domestic Wastewater and Industrial Discharge. Water 2017, 9, 409. [CrossRef]

13. Zheng, T.L.; Li, P.; Wang, Q.H.; Li, X.S.; Ai, H.Y. Pilot-scale experiments on brewery wastewater treatment and sludge reduction based on food chain predation. Desalin. Water Treat. 2014, 55, 1-10. [CrossRef]

14. Li, P.; Zheng, T.L.; Wang, Q.H.; Yang, S.; Liu, S.; Li, L.J.; Huang, P.K. Treatment of real high-concentration dyeing wastewater using a coagulation-hydrolysis acidification-multilevel contact oxidation system. Environ. Prog. Sustain. 2015, 34, 339-345. [CrossRef]

15. GB21/1627-2008. The Integrated Wastewater Discharge Standard of Liaoning Province, 1st ed.; Environmental Protection Bureau: Liaoning, China, 2008.

16. Miura, Y.; Hiraiwa, M.N.; Itonaga, T.; Watanabe, Y. Bacterial community structures in MBRs treating municipal wastewater: Relationship between community stability and reactor performance. Water Res. 2007, 41, 627-637. [CrossRef] [PubMed] 
17. Zhu, T.; Zhu, Y.F.; Fienko, U.; Xie, Y.H.; Zhang, K. Performance of multilevel contact oxidation in the treatment of wastewater from automobile painting industry. IOP Conf. Ser. Earth Environ. Sci. 2017, 51, 12-18. [CrossRef]

18. American Public Health Association (APHA). Standard Methods for the Examination of Water and Wastewater, 21st ed.; APHA: Washington, DC, USA, 2005.

19. Hu, M.; Wang, X.H.; Wen, X.H.; Xia, Y. Microbial community structures in different wastewater treatment plants as revealed by 454-pyrosequencing analysis. Bioresour. Technol. 2012, 117, 72-79. [CrossRef] [PubMed]

20. Xiong, J.B.; Liu, Y.Q.; Lin, X.G.; Zhang, H.Y.; Zeng, J. Geographic distance and PH drive bacterial distribution in alkaline lake sediments across Tibetan Plateau. Environ. Microbiol. 2012, 14, 2457-2466. [CrossRef] [PubMed]

21. Marzorati, M.; Wittebolle, L.; Boon, N.; Daffonchio, D.; Verstraete, W. How to get more out of molecular fingerprints: Practical tools for microbial ecology. Environ. Microbiol. 2008, 10, 1571-1581. [CrossRef] [PubMed]

22. Münch, E.V.; Lant, P.; Keller, J. Simultaneous nitrification and denitrification in bench-scale sequencing batch reactors. Water Res. 1996, 30, 277-284. [CrossRef]

23. Zeng, R.J.; Lemaire, Z.; Yuan, Z.; Keller, J. Simultaneous nitrification, denitrification, and phosphorus removal in a lab-scale sequencing batch reactor. Biotechnol. Bioeng. 2003, 84, 170-178. [CrossRef] [PubMed]

24. Ma, J.X.; Wang, Z.W.; Yang, Y.; Mei, X.J.; Wu, Z.C. Correlating microbial community structure and composition with aeration intensity in submerged membrane bioreactors by 454 high-throughput pyrosequencing. Water Res. 2013, 47, 859-869. [CrossRef] [PubMed]

25. Chiu, Y.C.; Lee, L.L.; Chang, C.N.; Chao, A.C. Control of carbon and ammonium ratio for simultaneous nitrification and denitrification in a sequencing batch bioreactor. Int. Biodeterior. Biodegrad. 2007, 59, 1-7. [CrossRef]

26. Ghyoot, W.; Verstraete, W. Reduced sludge production in a two-stage membrane assisted bioreactor. Water Res. 2000, 34, 205-215. [CrossRef]

27. Lee, N.M.; Welander, T. Reducing sludge production in aerobic wastewater treatment through manipulation of the ecosystem. Water Res. 1996, 30, 1781-1790. [CrossRef]

28. Wong, M.T.; Mino, T.; Seviour, R.J.; Onuki, M.; Liu, W.T. In situ identification and characterization of the microbial community structure of full-scale enhanced biological phosphorous removal plants in Japan. Water Res. 2005, 39, 2901-2914. [CrossRef] [PubMed]

29. Wolf, M.; Müller, T.; Dandekar, T.; Pollack, J.D. Phylogeny of Firmicutes with special reference to Mycoplasma( Mollicutes) as inferred from phosphoglycerate kinase amino acid sequence data. Int. J. Syst. Evol. Microbiol. 2004, 54, 871-875. [CrossRef] [PubMed]

30. Bertin, L.; Bettini, C.; Zanaroli, G.; Fraraccio, S.; Negroni, A.; Fava, F. Acclimation of an anaerobic consortium capable of effective biomethanization of mechanically-sorted organic fraction of municipal solid waste through a semi-continuous enrichment procedure. J. Chem. Technol. Biotechnol. 2012, 87, 1312-1319. [CrossRef]

31. Prashanthini, V.; Bui, X.T.; Chettiyappan, V. Simultaneous nitrification denitrification in a Batch Granulation Membrane Airlift Bioreactor. Int. Biodeterior. Biodegrad. 2014, 95, 139-143. [CrossRef]

32. Akao, S.; Tsuno, H.; Horie, T.; Mori, S. Effects of $\mathrm{pH}$ and temperature on products and bacterial community in L-lactate batch fermentation of garbage under unsterile condition. Water Res. 2007, 41, 2636-2642. [CrossRef] [PubMed]

33. Ahn, Y.; Choi, J. Bacterial communities and antibiotic resistance communities in a full-scale hospital wastewater treatment plant by high-throughput pyrosequencing. Water 2016, 8, 580. [CrossRef]

(C) 2017 by the authors. Licensee MDPI, Basel, Switzerland. This article is an open access article distributed under the terms and conditions of the Creative Commons Attribution (CC BY) license (http:/ / creativecommons.org/licenses/by/4.0/). 